\title{
O impulso formativo do pensamento crítico: racionalidade, verdade e constelação
}

Theformative impulseof critical thinking: rationality, truth andconstellation

Resumo O ensaio analisa a concepção de pensamento e subjetividade em Theodor Adorno, indicando os desafios educacionais que surgem dessa concepção. Defende uma concepção de verdade definida na dinamicidade histórica. A contraposição entre conhecimento e procedimento, as noções de evidência, constelação e conteúdo de verdade são decisivas para caracterizar o pensamento pós-metafísico e indicar os desafios na formação do sujeito segundo Adorno. Quando o conhecimento perde seu lugar pelo ideal de procedimento eficaz, ocorre o retardo da consciência, e a força do sujeito é abalada. A possível condição para reverter tal caracterização é admitir a ausência de evidência como impulso ao esclarecimento. Neste ponto é que se situa a noção de constelação e conteúdo de verdade e o impulso formativo do pensamento crítico.

PALAVRAS-CHAVE: Racionalidade, Formação, Consciência.

\begin{abstract}
The essayanalyze the concept ofthought andsubjectivity in TheodorAdorno, indicating theeducational challengesthat arisefromsuch a conception. Defends a conception of truth defined in the historical dynamicity. Thecontrastbetween knowledge andprocedure, the notionsof evidence, constellation and content of truth.are crucialto characterizethepost-metaphysical thoughtand indicatethe challengesin the formation ofsubject in Adorno. Whenthe knowledgeloses its place by the ideal of effective procedure, occurs the retardation of consciousness, and the strength of the subject is shaken. The conditionto reversethis characterizationis to admitthe absenceof evidenceastoimpulse ofenlightenment. In this time thatis situatedthe notion ofconstellationand content of truth andformative impulseof critical thinking.
\end{abstract}

KEYWORDS: Rationality, Formation, Consciousness. 


\section{Introdução}

Uma das marcas do pensamento de Theodor Adorno, a qual permite situá-lo como pós-metafísico, é sua concepção de verdade. A pontuação desta concepção indica um dos caminhos a partir do qual é possível situar, em sua proposta teórica, a arte e a educação. A formação do humano perpassa pela capacidade de realizar experiências; a expressão, sinal da capacidade comunicativa e criativa, exige, como condição para ser crítica, a imersão na experiência. $\mathrm{E}$ isto na tentativa de, em permanente confronto com o real, retirar significado. Não para estabelecer parâmetros estáticos de avaliação, mas para fornecer ao entendimento conteúdos que permitam a compreensão daquilo com o qual estou em relação. Por ser conteúdo, sofre a marca da transitoriedade, da dinâmica histórica.

Este ensaio pretende analisar a concepção de pensamento e subjetividade na perspectiva pós-metafísica de Theodor Adorno, enfatizando, nesta análise, o vínculo entre sua concepção de verdade e a constituição ou formação do humano. Neste autor, é levada ao extremo a crítica à formação da subjetividade e, consequentemente, define um novo olhar sobre quem é ou o que é aquilo que chamamos sujeito. A marca deste vínculo ocorre a partir de dois termos fundamentais: constelação e conteúdo de verdade.

Partindo de tais dados, o que defendo neste ensaio é a necessidade de a educação ser uma educação para a experiência, envolvendo a dialética do tato, bem como uma educação para a experiência intelectual, para além do ideal de formar seres capazes de proceder eficazmente. Proponho um itinerário teórico, resgatando os conceitos básicos internos ao referencial teórico, cujo ponto de partida é a concepção de verdade como portadora de núcleo histórico, seguindo para uma análise da tensão entre verdade e procedimento e, por fim, discuto a condição para haver ampliação da consciência, ou seja, a aceitação da ausência de evidência à razão e a necessidade de considerar a verdade como conteúdo e constelação.

\section{A concepção de verdade em seu núcleo histórico.}

As discussões em torno do conceito de verdade encontram uma indicação precisa ainda na Dialética do esclarecimento. A Dialética negativa e a Teoria estética ocupam lugar central nessa discussão, mas a referência à obra conjunta entre Adorno e Horkheimer é decisiva, pois nesta ocorre a fundamentação das discussões em torno deste conceito. $\mathrm{O}$ que resulta destas discussões permite situar Adorno como um autor pós-metafísico.

O núcleo da verdade é temporal, portanto, sua característica básica é a transitoriedade histórica. Somente este fato coloca Adorno em choque radical com a tradição filosófica que se criou desde a Grécia clássica. Nas palavras dele mesmo, assim é caracterizada sua teoria: "uma teoria que atribui à verdade um núcleo temporal, em vez de opô-la ao movimento histórico como algo imutável" (ADORNO; HORKHEIMER, 1985, p. 9) e a "verdade é constelação em devir" (ADORNO, 1995, p. 21), somente existindo como o que está em devir. Este fato demarca a concepção básica daquilo que é possível denominar de pensamento pós-metafísico. 
Dois problemas perpassam a discussão em torno deste tema, a partir de Adorno. O primeiro é a aniquilação da verdade em troca da eficácia no procedimento. A segunda discussão aponta para uma contraposição ao conceito grego aletheia. Se este termo indica aquilo não oculto, não escondido ou dissimulado e, portanto, alcançar a verdade é conseguir tirar o véu que encobre a realidade e trazer o fato à tona, em contraposição, a administração da vida gera o processo inverso: o encobrimento. Neste sentido, a verdade não se torna mais evidente, exigindo um radical esforço interpretativo, principalmente dos fatores que geram este encobrimento e, também, dos fatores que impedem ao pensamento vislumbrar o mundo sob o véu ideológico.

Este quadro não se vislumbra somente em questões teóricas, mas perpassa por toda formação do pensamento humano, principalmente em questões de educação regular em instituições de ensino. É visível a resistência ao ato de pensar e de se demorar sobre algo. A ânsia por fórmulas capazes de resolver imediatamente os problemas toma conta das atividades escolares e, ao se deparar com a necessidade de uso de um único ferramental - o pensamento rigorosamente orientado -, ocorre o bloqueio das energias do conhecimento, o que pode ser entendido como resistência à investigação teórica. Diante deste quadro, surge a Filosofia como alternativa formadora e propulsora do pensamento e busca pela verdade. Vamos analisar estes dois pontos de discussão, acima mencionados.

\section{Tensão entre verdade e procedimento: o retardo da consci- ência}

Uma consideração primeira: para Adorno, o problema decisivo ao pensamento e à própria Filosofia se situa na falência do elemento ativo, a saber, a concentração e a satisfação na verdade. Ativo não é aquele que domina procedimentos e, assim produz objetos. Esta ação pode estar carregada de automatismos. A verdadeira atividade coincide com a posse do elemento cognitivo, pois somente neste momento é que a ação passa a ser atribuída ao que executa. $O$ robô não é ativo, por mais que produza, pois neste está ausente o elemento do entendimento que, em outras palavras, é a satisfação da verdade. Deste modo, vincula-se o elemento ativo com a existência da força subjetiva, com a existência do sujeito, propriamente dito.

A falência deste elemento ativo se identifica com a incorporação do segundo elemento, a eficiência na operacionalidade, à qual vem acoplado a noção de representação do "objeto" e de eliminação do "sujeito". Um primeiro sentido desta eliminação está descrito no parágrafo anterior. Em relação à representação, percebemos o grave problema relacional que se origina dos ambientes virtuais. Não há mais a necessidade de encontro efetivo e a dinâmica que envolve o tato e o confronto direto é substituída pela dinâmica da visão e da audição destituída de efetividade sensível imediata. Esta representação do outro em um encontro desvinculado da experiência, promovido pelos ambientes virtuais, acaba gerando a imediata pobreza de experiência, a inexistência de padrões éticos que somente ocorrem quando temos o corpo em contato. Subjetividade vazia é o que marca o indivíduo moderno, pois a condição para haver solidez no $e u$ é negada na relação ausente de corpo e, portanto, não efetiva. 
A patologia do contato é marca de um processo histórico de formação para o enclausuramento do indivíduo em si mesmo, gerando o retardo da consciência: seres que não conseguem se sentir envolvidos, tampouco imediatamente responsáveis ou com senso de responsabilidade efetivo. Neste sentido, educar é educar a sensibilidade, a percepção, o modo de entrar em contato. Utilizando um termo de Hermann, a educação deve desenvolver o outro da razão, mediante, exatamente, o critério da experiência estética, ou seja, a experiência com o sensível. Em suas palavras, devemos romper com a ilusão

de que o ser verdadeiro do homem está no conhecimento e na consciência [...], nosso acesso ao mundo das escolhas éticas dispensaria a sensibilidade e a intuição. [...] $\mathrm{O}$ que põe em movimento esse outro lado da razão - o sentimento, a sensibilidade, as emoções e o corpóreo - é a experiência estética. (HERMANN, 2010, p. 15).

Estamos diante da abertura ao outro e àquilo que se constitui em sua própria promessa de vida, pois a experiência com o corpóreo nos põe diante de algo que, ao mesmo tempo em que não nos é familiar, nos lembra que existem outras formas de compreender e de viver no mundo. Ou seja, nos põe diante da alteridade. Outro aspecto a ser considerado é a tensão entre intelecto e moralidade, pois a erudição pode construir seres incapazes de perceber efetivamente o outro em sua fragilidade ou em sua riqueza constituiva. Daí a importância de conectar à dimensão intelectual o princípio da estética. A existência de um outro se constitui em um enorme desafio ético, e o desafio é conseguir "levar o outro a sério, de entregar-se à sua forma de ver o mundo e a acompanhar seu modo de pensar e de agir [...], da disposição de nos entregarmos ao risco de perder as certezas que vinham orientando nosso modo de viver e de nos relacionarmos com os outros"(FLICKINGER, 2011, p. 04). Retomando o termo em questão - verdade -, qual é a verdade do outro, para além de minha representação? Desta compreensão pode resultar a riqueza ou pobreza de consciência, pois quando acredito poder substituir o objeto pelo objeto de minha representação, ou quando admito que o outro somente exista por ter passado pela minha percepção e entendimento, então a verdade se converte em ideologia reducionista e anuladora da riqueza constitutiva deste outro. A verdade do outro é seu em-si e devir, e não o seu para-mim; é seu conteúdo de consciência próprio e insubstituível; é sua marca histórica constituidora de sua identidade. É baseado nestes dados que defendo a urgência da educação que vise desenvolver a satisfação pela verdade, a riqueza de conteúdo, não somente a operacionalidade. guinte modo

A conduta adequada poder-se-ia caracterizar, em sentido filosófico, do se-

não é agitação afanosa nem o ficar parado matutando, mas sim o olhar demorado sobre o objeto, sem querer forçá-lo. A disciplina científica em voga requer do sujeito que se apague a si mesmo em prol da primazia da coisa ingenuamente presumida. A isto se opõe a filosofia. O pensar não deve reduzir-se ao método, a verdade não é o resto que permanece após a eliminação do sujeito. Pelo contrário, este deve levar consigo toda sua inervação e experiência na observação da coisa para, segundo o ideal, perder-se nela. (ADORNO, 1995, p. 19). 
Falar em educação é propor tais experiências, não procedimental em relação ao outro, mas no sentido de educar na habilidade de realizar experiências de pensamento, resistindo ao previamente pensado.

\section{A perda da evidência e o impulso ao esclarecimento}

Com o uso do termo "perda da evidência" quero significar algo diferente do sentido adorniano desenvolvido em sua Teoria estética, de perda da evidência artística. Nesta obra está desenvolvida a perspectiva de que, "perante aquilo em que se torna a realidade, a essência afirmativa da arte, esta essência inelutável, tornou-se insuportável” (ADORNO, [s.d], p. 12). Por causa disto é que a arte assume o caráter de tensão com a realidade e se mostra como "antítese social da sociedade" (p. 19). Na possibilidade de admitir a arte como cópia do real, em Adorno isto ocorre "na medida em que a este fornecem o que lhe é recusado no exterior e assim libertam daquilo para que as orienta a experiência externa coisificante" (s.d, p. 15).

Os elementos aterrorizadores, presentes na realidade, remetem a uma atualização do medo e da angústia mítica. Tais elementos podem ser resumidos na afirmação das Minimamoralia, quando é afirmado o "fato de que não há mais vida", sendo evidente a presença de "poderes objetivos que determinam a existência individual até o mais recôndito nela" (ADORNO, 1993, p. 7). Este ponto de partida da referida obra indica o fato de que, não havendo mais vida, como permanecer no caráter de afirmação da realidade?

É neste ponto que reside a compreensão adorniana do caráter esclarecedor da verdade: desenvolver a consciência dos elementos que levam à negação da vida. Embora Adorno atribua à arte um papel de crítica, é via educação que se torna possível a ampliação da consciência, em um incisivo impulso esclarecedor. Desenvolver consciência é tornar algo evidente, trazer ao entendimento estes poderes que determinam a existência individual, a ponto de gerar a ausência de vida. A perda da evidência pode ser entendida como obscurecimento que impede a compreensão dos fatos, o qual tem sua origem nos interesses ideológicos que anulam o desenvolvimento da consciência ou, ainda, impedem a consciência de se achegar aos fatos. Esta é a tensão entre aletheia e pseudos. Esta perda da evidência deve sofrer o antagonismo de ações permeadas por um radical esforço educativo. Foi mediante processo formativo que o real passou a ser não passível de consciência. É somente mediante fervorosos projetos educacionais que será possível devolver à consciência seu poder de compreensão.

Como compreender, em Kant, a sensibilidade, a percepção que intui os objetos, a partir da ausência de evidência, em Adorno? Em relação à Kant, o poder da sensibilidade, regida pelas estruturas internas ao sujeito, nas noções de tempo e espaço, se tornam insuficientes. Ainda na introdução da primeira crítica há a seguinte afirmação:

que outra coisa poderia despertar e pôr em ação a nossa capacidade de conhecer senão os objetos que afetam os sentidos e que, por um lado, originam por si mesmos as representações e, por outro lado, põe em movimento a nossa faculdade intelectual e levam-na a 
compará-las, ligá-las ou separá-las, transformando assim a matéria bruta das impressões sensíveis num conhecimento que se denomina experiência. (KANT, 2001, B1, p. 36).

Seguindo a argumentação acima, a percepção dá um material já desqualificado, gerando um erro no processo inicial que leva à síntese e ajuizamento operados pelo entendimento. A síntese operada pelo entendimento está dentro de uma tríade no sistema kantiano, a qual possibilita o conhecimento a priori dos objetos. Conforme a Crítica da Razão Pura (em B 104), esta tríade é formada pelas seguintes funções:

a) primeiro passo: o diverso da intuição pura;

b) segundo passo: a síntese desse diverso pela imaginação;

c) terceiro passo: "os conceitos, que conferem unidade a esta síntese pura e consistem unicamente na representação desta unidade sintética necessária”.

A discussão, neste ensaio, não está centrada na possibilidade dos conhecimentos sintéticos a priori, mas na possibilidade de a sensibilidade fornecer material confiável ao entendimento. Deste modo, se postula o núcleo do conhecimento como resultado do jogo entre entendimento e experiência, estando na possibilidade de experiência efetiva a condição para um ajuizamento com conteúdo de verdade.

Não havendo possibilidade imediata de a sensibilidade dar o objeto em seu efetivo sentido, o entendimento não consegue operar a síntese e, consequentemente, ter a fonte para verdade alguma. Vejamos qual o itinerário kantiano: "a espontaneidade do nosso pensamento exige que este diverso seja percorrido, recebido e ligado de determinado modo para que se converta em conhecimento. A este ato dou o nome de síntese" (KANT, 2001, B102, p. 108). Continuando a argumentação, encontramos uma definição mais clara do que é o momento da síntese: "na acepção mais geral da palavra, $o$ ato de juntar, umas às outras, diversas representações e conceber a sua diversidade num conhecimento" (B103, p. 109).

Como consequência deste ato sintético ocorre o ato de pensamento e que promove pensamento, no sentido de gerar conceito, o qual é, em Kant, "a primeira origem do nosso conhecimento" (B103, p. 109). Estamos diante de um diverso da intuição sensível, o qual tem como característica o ajuizamento, o discurso: "o conhecimento de todo o entendimento, pelo menos do entendimento humano, é um conhecimento por conceitos, que não é intuitivo, mas discursivo" (B93, p. 102).

É este itinerário que fica bloqueado. E uma ampliação da consciência somente ocorreria com a mudança não apenas no sentido, mas na possibilidade de conhecimento. $\mathrm{O}$ conhecimento discursivo, por mais que seja importante, deve ser precedido por algo que está fora do domínio conceitual do sujeito transcendental: a noção de verdade objetiva. $\mathrm{O}$ sujeito transcendental queda insuficiente em se tratando da possibilidade de conhecimento por não ser dado às suas estruturas material verídico para sua síntese e ajuizamento. E isto devido ao fato de negar a verdade em seu núcleo sensível, concreto, presente no objeto e disponibilizado ao sujeito somente via radical imersão na experiência. É neste momento que podemos entender claramente a afirmação adorniana na Dialética negativa, a qual aponta para o fato de que o"concei- 
to é um momento como outro qualquer na lógica dialética". E, da "necessidade que a filosofia tem de operar com conceitos não se pode fazer-se a virtude de sua prioridade" (ADORNO, 2009, p. 23).

Sua não prioridade se justifica na discussão que envolve dois termos decisivos para Adorno, os quais servirão de impulso à compreensão do momento específico que a razão interpretativa e a capacidade conceitual ocupam dentro deste quadro teórico. Refiro-me aos termos constelação e conteúdo de verdade.

Em se tratando do ajuizamento e expressão, vale destacar: "O critério do verdadeiro não é sua imediata comunicabilidade a alguém. Agora que todo passo em diração à comunicação vende e falsifica a verdade, deve-se resistir a coação quase universal de confundir o conhecido com sua comunicação e, inclusive, situá-la acima dele" (ADORNO, 2009, p. 49). O fato de ser dito não justifica ser verdade. Toda forma de comunicação pode ser caminho em direção ao ocultamento, a não evidência, na direção de uma pseudo comunicação. O juízo pode representar a falsa consciência. Este fator reafirma a situação problema que bloqueou o itinerário teórico kantiano.

\section{Constelação e conteúdo de verdade: marcas do pensamento pós-metafísico em Adorno}

O termo constelação, próprio de sua obra Teoria estética, remete ao quão insuficiente é um conceito em sua tentativa de capturar o real. A razão interpretativa deve se comportar como a arte, daí uma racionalidade estética, semelhante a "um ímã num campo de limalha de ferro. Não apenas os seus elementos, mas também a sua constelação, o especifimente estético que se atribui comumente ao seu espírito, remete para este Outro" (ADORNO, [s.d.], p. 18). Em outra passagem, assim é exposto: "A arte tem o seu conceito na constelação de momentos que se transformam historicamente; fecha-se assim à definição" (p.12).

Esta racionalidade interpretativa exige uma característica: a sensibilidade. Em outras palavras, é uma racionalidade em radical vínculo com a efetividade da experiência. Deste modo, a sensibilidade não é algo a parte, um momento primeiro e rapidamente superado pelo momento intelectivo. Converte-se na condição para apreender o objeto, por isso a necessidade de sua permanente renovação.

Como é possível dizer algo? Somente via constelação, ou seja, na abertura do devir histórico e na capacidade de congregar sentido mediante a percepção dos conteúdos de verdade. Exatamente por não ser imutável, a verdade se constitui em conteúdo, a consciência que se expressa em confronto com a constelação de momentos que formam um objeto. $\mathrm{O}$ que forma o objeto? A totalidade de seus momentos, sua constelação. Em se tratando do termo consciência, é possível afirmá-la como sendo o conteúdo interno ao sujeito, o qual equivale ao nível de experiência que tenho.

Adorno utiliza o conceito constelação para trazer, ao centro da experiência estética, a riqueza constitutiva do outro. Não é mais um único olhar, segundo uma única lógica interpretativa, que consegue capturar o real, retendo-o em uma cápsula conceitual, mas, ao contrário, um jogo de forças constitutivas entra em ação quando 
a relação de diferenciados ocorre. Este jogo segue a regra de que um único conceito não contempla a totalidade do objeto, mas, diante da constelação de sentido, diversos conceitos dialogam visando a compreensão.

O termo sedimento da história, no texto Sobre Sujeito e Objeto, remete claramente ao quanto a consciência é determinada pela relação com aquilo que ela mesma não é, o Outro. Somos resultado da história e, como tal, não há a menor possibilidade em persistir sem mais na captura conceitual cuja pretensão é convencionar o sentido. Em contraposição com o idealismo, no qual "pensar é conhecer por conceitos" (KANT, 2001, B 94, p. 103), temos o pensamento como algo que "não se esgota nem no processo psicológico nem na lógica formal pura intemporal. É um modo de comportamento ao qual é imprescindível a referência àquilo com o qual se relaciona" (ADORNO, 1995, p. 18).

A sensibilidade não fornece e, tampouco, o entendimento interioriza, por completo seus objetos. Duas vias impedem este fornecimento e esta interiorização. Por um lado, temos a perda da evidência, conforme analisado no item anterior. Por outro lado, ocorre o limite interpretativo da razão, a qual gera nada menos que a consciência limitada. Em ambos percebe-se a ausência da possibilidade de experiência, que é falha na dialética entre pensamento e realidade. A necessidade da Filosofia está em ser força de reflexão sobre o outro, a alteridade, não nele mesmo e por ele mesmo, mas a partir dele, em sua não igualdade impulsionadora da experiência. Na terra de iguais, não se tem motivo para pensar. O pensamento ocorre por causa da diversidade, da tensão, da dinâmica caracterizada pela contradição.

Havendo conteúdo de verdade, estando o outro imerso em uma constelação de momentos que o constituem, isto remete à exigência da razão interpretativa, a qual se contrapõe à clareza de sentido, pois, quando correr clareza de sentido, fica comprometida a necessidade interpretativa. A exigência de interpretação é considerada, deste modo, exigência filosófica fundante. $\mathrm{O}$ outro, em sua constelação e conteúdo de verdade, não é somente intuitivo. Enquanto empiria é possível admitir tal redução. Porém, se houvesse esta redução, a fascinação de sua percepção imediata seria suficiente e, deste modo, perder-se-ia toda riqueza constitutiva que está além do conteúdo dado pelos sentidos. Em sua constelação e conteúdo de verdade, o outro é impulso interpretativo, motivo de pensamento e, partindo dele, conteúdo filosófico. É filosófico por não se reduzir à intuição, mas apontar estímulo ao pensamento - isto converteu aquilo que na teoria do conhecimento tradicional era tido como objeto em algo qualitativamente distinto: o outro.

Onde se localiza o sujeito desta razão interpretativa e quando é possível dizer que tal sujeito existe? Adorno situa esta possibilidade afirmando que o"indivíduo se converte em sujeito na medida em que, graças a sua consciência individual, se objetiva tanto na unidade de si mesmo quanto de suas experiências: ambas podem ser negadas aos animais" (ADORNO, 2009, p. 53). Esta consciência individual pode ser aproximada, salvo algumas restrições, à autoconsciência kantiana. Irei expor aspectos da teoria kantiana acerca disto para, após, estabelecer as discussões. 
Na Crítica da Razão Pura, ocorre a indicação clara do que significa, para o ser humano, o reconhecimento da síntese das representações como propriedade individual. Todas as representações constituem uma totalidade/unidade na autoconsciência, a qual é denominada “unidade transcendental da autoconsciência”. Esta unidade significa que "as diversas representações não seriam representações minhas se não pertencessem na sua totalidade a uma autoconsciência". É a "ligação originária" de todas as representações. Para Kant, a consciência empírica é dispersa e sem referência à identidade do sujeito. Tal referência à identidade do sujeito se estabelece "porque acrescento uma representação a outra e tenho consciência da sua síntese". A ligação originária à identidade do sujeito, ocorrida pela autoconsciência, somente ocorre devido exatamente à consciência da síntese de tais representações num mesmo sujeito, gerando, assim, o eu idêntico. Por esta unidade de todas as representações na consciência é possível formar, inclusive, a unidade do sujeito. Se assim não o fosse, "teria um eu tão multicolor e diverso quanto tenho representações das quais sou consciênte" (cf. KANT, 2001, B 132-134, p. 131ss.).

Partindo de tais referenciais, é possível estabelecer um paralelo entre a concepção kantiana da formação da autoconsciência, com a concepção adorniana de tal formação. Um passo decisivo dado por Adorno está na relevância que a continuidade histórica tem na formação do eu. Com o desaparecimento da consciência da continuidade histórica ocorre não somente a perda da referência quanto ao devir histórico, mas o esfacelamento da consciência que não reconhece a totalidade dos momentos como seu constitutivo essencial. Isto remete ao fato de que a autoconsciência deve significar a existência do eu idêntico, pois, apesar de, no devir histórico, na tensão histórica de todo encontro e busca da verdade, não haver a identidade entre sujeito e seu outro, apesar disto, as experiências constituídas pelo indivíduo devem ser representadas como propriedade única de si mesmo.

É a noção de que, apesar da não possibilidade de representar a totalidade do outro em minha consciência, aquilo que se representa é conteúdo próprio e forma a autoconsciência. Isto tem consequência em questões morais, pois, diante da impossibilidade de representação plena, se exige a relação permanente, o encontro constante e, na perspectiva adorniana, este encontro deve ocorrer de modo a permitir uma situação na qual é possível ser diferente sem ter medo. Ocorre o entendimento que toda representação é representação de um momento histórico, de modo que a razão permanece em estranhamento diante do real. É “a síntese não violenta do disperso” (ADORNO, [s.d.], p. 165), que ocorre apesar de permitir ao outro continuar sendo ele, para além do meu conteúdo de consciência. Em se tratando de consciência moral, Adorno argumenta que esta, na doutrina kantiana, é a "voz da lei moral”, e somente se converte em consciência devido à força de coerção social que se impõe mediante seu caráter de universalidade e necessidade. O problema para o filósofo da Dialética negativa está no fato de não ser possível identificar liberdade com coerção.

Retornando ao problema da representação e utilizando outra análise da Teoria estética, percebe-se que a relação da razão interpretativa, diante da obra de arte, é a mesma relação que esta razão deve estabelecer com tudo o que entra em seu círculo de contato: 
Se uma obra se abre inteiramente, atinge-se então a sua estrutura interrogativa e a reflexão torna-se obrigatória; em seguida, a obra afasta-se para, finalmente, assaltar uma segunda vez com o «o que é isto?» aquele que se sentia seguro da questão. É possível, porém, reconhecer como constitutivo o caráter enigmático lá onde ele falta: as obras de arte que se apresentam sem resíduo à reflexão e ao pensamento não são obras de arte. (ADORNO, [s.d.], p. 142).

Este caráter de instigação à razão e, consequentemente, de permanente enriquecimento da experiência, eleva o outro, este que era considerado tradicionalmente objeto, à dignidade de estar-aí com riqueza constitutiva para além da minha apreensão. Parafraseando Adorno, o "objeto" que se apresenta sem resíduo à reflexão e ao pensamento não é "objeto".

Educacionalmente se impõe o desafio de constituir a consciência verdadeira, na exigência de que "o princípio do esclarecimento da consciência seja aplicado na prática educacional", principalmente diante do fato de que

\begin{abstract}
a própria organização do mundo em que vivemos e a ideologia dominante [...], ou seja, a organização do mundo converteu-se a si mesma imediatamente em sua própria ideologia. Ela exerce uma pressão tão imensa sobre as pessoas, que supera toda a educação. Seria efetivamente idealista no sentido ideológico se quiséssemos combater o conceito de emancipação sem levar em conta o peso imensurável do obscurecimento da consciência pelo existente. (ADORNO, 2003, p. 142-143 - grifo nosso).
\end{abstract}

Isto explica o motivo pelo qual a escola corre o risco de sofrer de insuficiência formativa. Frente à pressão do mundo sobre os indivíduos, é frequente que sua consciência sofre muito mais o impacto por tal pressão do que pela ação pedagógica desenvolvida por um professor ou instituição escolar.

\title{
Considerações finais
}

Tendo presente que o objetivo deste ensaio foi analisar a concepção de pensamento e subjetividade na perspectiva pós-metafísica de Theodor Adorno, enfatizando, nesta análise, o vínculo entre sua concepção de verdade e a constituição ou formação do humano, cabe destacar alguns tópicos a fim de sintetizar as contribuições que se vislumbraram após esta construção teórica.

Em relação à caracterização de Adorno como um filósofo pós-metafísico, a ênfase se encontra na caracterização do núcleo da verdade como algo temporal. Deste modo, a característica básica é a transitoriedade histórica. Somente este fato coloca Adorno em choque radical com a tradição filosófica que se criou desde a Grécia clássica. Partindo desta concepção, vislumbra-se a necessidade de a escola permitir que o ser humano faça a experiência do mundo, não como uma instância passageira rumo ao conceito estático, mas como um permanente instigar à racionalidade, como algo portador de significado para além do atribuído pela interpretação. Isto permite a evolução e o espírito de busca, próprio do processo de esclarecimento, o que não ocorre quando este núcleo acima referido for negado. 
Diante da discussão em torno do problema que envolve a verdade e a perda da evidência, vale reafirmar a necessidade garantir à razão o acesso ao fato, para além de toda ideologia ou tendências interpretativas. A condição de permanecer na relação com o outro garante que o entendimento, para usar a linguagem kantiana, esteja em posse de material confiável para exercer sua função de síntese. Por isso a necessidade de renovação permanente da experiência, a fim de permitir o ajuizamento seguro. A educação centrada na no desenvolvimento das condições para o ser humano constituir um modo de vida próprio, por mais que isso envolva a constante interação com os outros, os diferentes de si, deve ter como horizonte de sentido a preparação dos indivíduos para reconhecer a riqueza constitutiva de cada ser. Ao mesmo tempo deve tornar as pessoas conscientes da necessidade de abandonar a racionalidade fechada em si mesma, estando apto para o diálogo construtivo e gerador de sentido de mundo. Educar é, em última instância, compor a constelação.

\section{Referências}

ADORNO, T.W.; HORKHEIMER, M. Dialética do Esclarecimento: fragmentos filosóficos. Tradução de Guido Antonio de Almeida. Rio de Janeiro: Jorge Zahar Editor, 1985, p. 254. 2009, p. 351.

Dialética negativa. Tradução de Marco A. Casanova. Rio de Janeiro: Jorge Zahar. ed.

. Educação e emancipação. 3. ed. Tradução de Wolfgang Leo Maar. São Paulo: Paz e Terra, 2003, p. 190.

. Minima Moralia: reflexões a partir da vida danificada. Tradução de Luiz Eduardo Bicca. 2 ed. São Paulo: Ática, 1993, p. 216.

. Palavras e sinais: modelos críticos 2. Tradução de Maria Helena Ruschel. Petrópolis: Vozes, 1995 , p. 259.

[s.d]. Teoria estética. Lisboa: Edições 70, (Arte e Comunicação, n.14), 294 p.

FLICKINGER, H. G. A caminho de uma pedagogia hermenêutica. Campinas: Autores Associados, (coleção Educação contemporânea), 2011, p. 200.

HERMANN, N. Autocriação e horizonte comum: ensaios sobre educação ético-estética. Ijuí: Ed. Unijuí. - (coleção Fronteiras da educação), 2010, p. 171.

KANT, I. Crítica da razão pura. Tradução de Manuela Pinto dos Santos e Alexandre Fradique Morujão. 5 ed. Lisboa: Fundação Calouste Gulbenkian, 2001.

* Professor Doutor da Universidade do Oeste de Santa Catarina, Joçaba, Santa Catarina, Brasil.

\section{Correspondência}

Mauricio João Farinon - Universidade do Oeste de Santa Catarina, Rua Getúlio Vargas, 2125, Bairro Flor da Serra. CEP: 99052900 - Joaçaba, Santa Catarina, Brasil.

E-mail: mauricio.farinon@unoesc.edu.br

Recebido em 14 de julho de 2014

Aprovado em 08 de agosto de 2014 
